\title{
Der Antagonist
}

Liebe Leserinnen, liebe Leser,

etwas pointiert möchte ich hier einen Aspekt meines Themas von Heft 04/ 2015 darstellen: Am Anfang seiner Geschichte war um den Computer Bewunderung, Unsicherheit und Sorge. Das Potential einer Denkmaschine beängstigte die Nachdenklichen. Ein heftig debattiertes Thema war der Bürger, dessen Daten auf den Magnetspeichern geführt und vom Computer automatisch verarbeitet werden. Ein Computer war seinerzeit in der Regel raumfüllend, teuer in Anschaffung und Betrieb; kein Anschaffungsgegenstand für den kleinen Mann. Weil er deshalb größeren Verwaltungen vorbehalten war, sah man im Computer ein Herrschaftsinstrument, das den Bürger berechenbar und manipulierbar macht. Die Sorge darum führte zum Datenschutz. Der Gesetzgeber legte ein generelles Verbot auf die Verarbeitung personenbezogener Daten und nahm nur das Notwendige vom Verbot aus. Darüber hinaus beließ er dem geschützten Subjekt die Freiheit, auf Schutz zu verzichten. Ob so oder so: Es berührte den kleinen Mann nicht so sehr. Was ihn berührte, war Bürokratie: gesetzlich erforderliche Benachrichtigungen über die Speicherung von Daten und gelegentlich Auskunftsverweigerungen mitVerweis auf Datenschutz.

1983 erreichten die politisch Engagierten, dass sich anlässlich ihrer Klage gegen das Volkszählungsgesetz das Bundesverfassungsgericht mit dem Datenschutz befasste. Zur Grundlegung des Urteils leitete es aus dem allgemeinen Persönlichkeitsrecht des Art. 2 Abs.1 GG in Verbindung mit Art.1 Abs.1 GG das „Recht auf Informationelle Selbstbestimmung" ab. Dieses besondere Recht war demnach kein neues Grundrecht und brachte deshalb substantiell nicht Neues. Dennoch erbrachte das Bundesverfassungsgericht mit der Ableitung aus den Grundrechten das zweite prägende Ereignis zum Datenschutz nach dem BDSG von 1977. Es gab dem Datenschutz Verfassungsrang.„Datenschutz" und "Informationelles Selbstbestimmungsrecht" wurden fortan nahezu synonym gebraucht.

Was aber hat sich am Datenschutz als selbstbestimmt gezeigt? Es lief anders als gedacht. Er entwickelte sich zu einer Dienstleistung, bzw. zu einem Recht auf diese Dienstleitung. Die Normadressaten, öffentliche und private Verwaltungen, implementierten die Bestimmungen des Gesetzes, ohne dass der Geschützte selbst darauf Einfluss hatte. Das Gebotene reichte zumeist für seine Bedürfnisse aus, zumal er es öffentlich überwacht wusste. Die Dienstleistung bewährte sich. Der Geschützte hat über das Gewährte hinaus auch aktive Rechte an seinen Daten; er kann sie korrigieren lassen und ihre Verarbeitung fallabhängig verhindern. Die Rechte in Anspruch zu nehmen, erfordert aber Sachkenntnisse und Mühe. Der Begünstigte wägt Aufwand gegen Bedeutung ab. Das lässt ihn von selbstbestimmtem Tätigwerden eher absehen. Damit nimmt sein aktives Interesse an der Sache ab und verliert sich umso mehr, je mehr er passiv der Dienstleistung vertraut. Er hat ein Recht auf Schutz seiner Daten, verhält sich aber nicht, wie vom Bundesverfassungsgericht gedacht, als ihr selbstbestimmender Wächter.

Dennoch hat das Recht auf informationelle Selbstbestimmung eine bemerkenswerte Bedeutung entwickelt. Im Volkszählungsgesetz-Urteil formuliert, bestätigt es die rechtliche Grundlage des Datenschutzes; es unterstützt zweifellos seine Maximen. Doch schließt es - nolens volens - das Recht des Geschützten ein, sich auch gegen den Datenschutz zu entscheiden. Eben diese negative Freiheitskomponente hat mit der Zeit an Bedeutung gewonnen. Die Geschäftspartner des Geschützten und der Staat haben ein zumeist legitimes Interesse daran, möglichst viel über seine persönlichen Verhältnisse zu erfahren; sie brauchen seine Daten. Selbstbestimmend kann er die Daten freigeben. Das tut er; meist durch die sich bietenden Umstände verleitet. Es wird zum allgemeinen Geschäftsgebrauch. Er verzichtet auf Datenschutz, d.h. auf etwas, das ihm "gefühlt" nichts kostet, das er aber mit seinem informationellen Selbstbestimmungsrecht leicht versilbern kann.

So meine ich, liebe Leserinnen und Leser: Man darf den Datenschutz nicht mit dem Grundrecht verwechseln. Es kann auch sein Antagonist sein.

Mit freundlichen Grüßen, Ihr

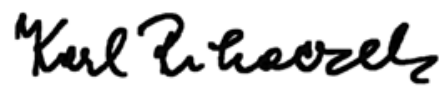

